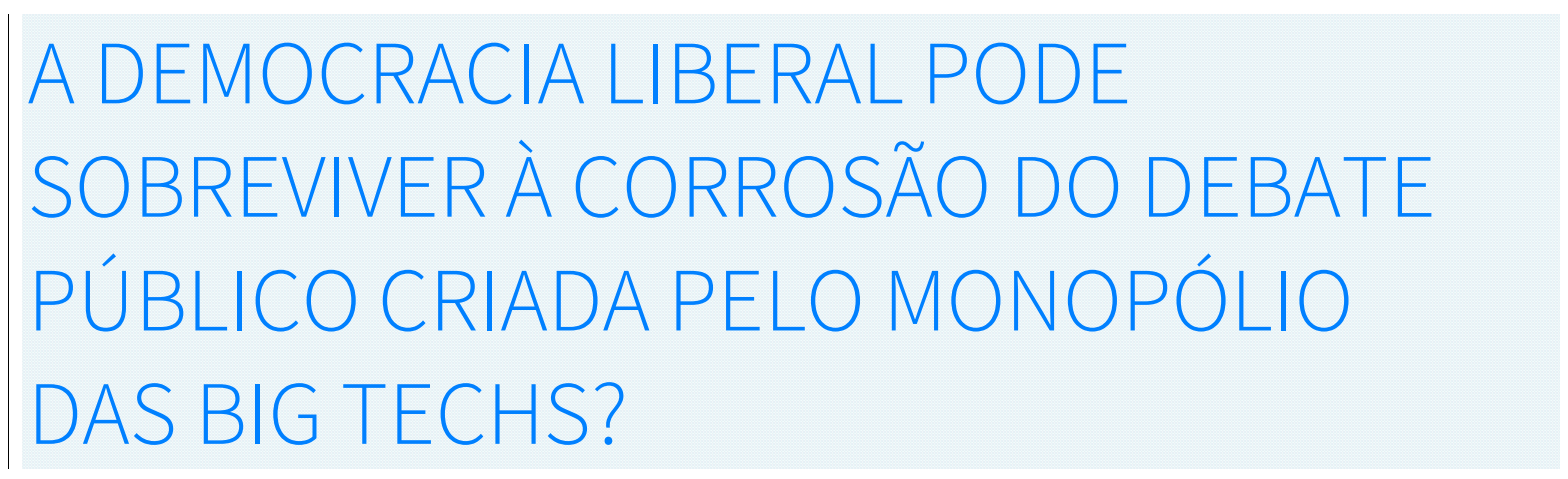

Can the liberal democracy survive the corrosion of public debate promoted by the big tech monopoly?

\title{
Renata Mielli
}

Jornalista, graduada em Comunicação Social pela Faculdade Cásper Líbero. Doutoranda no Programa de Ciências da Comunicação da Escola de Comunicação e Artes da Universidade de São Paulo (PPGCOM/ECA/USP). É coordenadora do Centro de Estudos da Mídia Alternativa Barão de Itararé. Integra a Câmara de Universalização e Inclusão Digital do Comitê Gestor da Internet no Brasil (CGI.br) e a Comissão Permanente de Comunicação do Conselho Nacional de Direitos Humanos. Membro do Conselho de Comunicação da Câmara dos Deputados. É membro da Coalizão Direitos na Rede. Foi Coordenadora Geral do Fórum Nacional pela Democratização da Comunicação (FNDC) entre 2016-2020 e integrou a Executiva do FNDC entre 2011-2020. Tem experiência na área de Comunicação, atuando principalmente nos seguintes temas: Políticas de Comunicação, Radiodifusão, Comunicação Pública, Internet, Plataformas de Redes Sociais, Marco Civil da Internet, Big Data, Inteligência Artificial e Proteção de Dados Pessoais.

\section{Larissa Ormay}

Doutora em Ciência da Informação pela Universidade Federal do Rio de Janeiro (UFRJ) e pelo Instituto Brasileiro de Informação em Ciência e Tecnologia (Ibict), Mestre em Ciência Política pela Universidade Federal Fluminense (UFF) e graduada em Direito pela Pontifícia Universidade Católica do Rio de Janeiro (PUC-Rio).

\section{Luana Meneguelli Bonone}

Doutoranda em Comunicação e Cultura pela Universidade Federal do Rio de Janeiro (UFRJ), integrante do Grupo Marxiano de Pesquisa em Informação, Comunicação e Cultura (ComMarx), mestra em Comunicação e Semiótica pela Pontifícia Universidade Católica de São Paulo (PUC-SP), com especialização em Democracia Participativa, e graduação em Comunicação Social pela Universidade Federal de Minas Gerais (UFMG). Atualmente é professora de Redação do programa Pré-Vestibular Social do Centro de Ciências e Educação Superior a Distância do Estado do Rio de Janeiro (CEDERJ/CECIERJ) e pesquisadora da cátedra de Educação do Centro de Estudos e Memória da Juventude (CEMJ). 


\section{RESUMO}

O emprego das Big Techs como plataformas de trocas simbólicas representou uma ruptura na maneira como o debate público se organiza na sociedade. Este artigo vai analisar como o uso de dados pessoais e a monetização para parametrizar as tarefas dos algoritmos de aprendizagem de máquina que estruturam essas trocas estão ampliando a fragmentação social e o aprofundamento da crise da democracia liberal. O modelo econômico dessas plataformas, apoiado no extrativismo de dados e no patenteamento de suas ferramentas, somado aos obstáculos jurisdicionais para impor regulação a essas empresas são um entrave para enfrentar a disseminação em grande escala da desinformação e do negacionismo que fertilizam o crescimento do autoritarismo e de protofascismos em todo o mundo. Nesse sentido, o artigo propõe uma reflexão sobre a insuficiência de regulações pontuais para mitigar os efeitos deletérios da circulação de informação mediada em plataformas.

Palavras-chave: plataformas de internet; big techs; algoritmos; internet pública.

\section{ABSTRACT}

The use of Big Techs as platforms for symbolic exchanges represented a rupture in the way public debate is organized in society. This article will analyze how the use of personal data and monetization to parameterize the tasks of machine learning algorithms that structure these exchanges are increasing social fragmentation and deepening the crisis of liberal democracy. The economic model of these platforms, based on data extraction and the patenting of their tools, added to the jurisdictional obstacles to impose regulation on these companies, are an obstacle to facing the large-scale dissemination of disinformation and denial that fertilize the growth of authoritarianism and of proto-fascisms around the world. In this sense, we propose a reflection on the insufficiency of specific regulations to mitigate the harmful effects of the circulation of information mediated in platforms.

Keywords: internet platforms; big techs; algorithms; public internet. 


\section{Introdução}

A crise da democracia liberal que atinge países pelo mundo, particularmente nos últimos i5 anos, tem tido como um de seus desdobramentos o crescimento de forças políticas e governos de vieses fascistas e autoritários. Entre os fatores que deram origem a este cenário estão os impasses do próprio capitalismo, agravados com a crise econômica de 2008, que colocou em xeque as bases do chamado estado de bem-estar social, o qual garantia um rol mínimo de proteção social e direitos trabalhistas. Esse modelo se transformou num obstáculo para a manutenção da acumulação capitalista nesta fase de mudanças de paradigmas na produção.

Nesse contexto, o capital buscou nas novas Tecnologias da Comunicação e Informação (TICs) a saída para atender as demandas de desenvolvimento do modo de produção capitalista, acelerando o processo de rotação do capital em termos de quantidade e qualidade e como meio para manter o rentismo e as altas taxas de acumulação. A internet - em particular as plataformas sociodigitais - é o elo econômico, cultural e social que impôs novas dinâmicas para os fluxos de capitais, para a comunicação e para as formas de relacionamento entre pessoas, organizações e Estados.

Para justificar os ataques ao modelo democrático liberal, bem como a ofensiva conservadora, os apoiadores do capitalismo precisavam de uma investida ideológica para pavimentar o terreno e obter um mínimo de apoio às restrições de direitos e da democracia. Para isso, foi feito uso intensivo das TICs, com base em estratégias de microssegmentação de mensagens possibilitadas pelo uso de dados pessoais e inteligência artificial, aproveitandose do modelo econômico das plataformas e das dinâmicas de captura da atenção e mobilização das emoções que passaram a dominar o novo espaço público de debates no interior das plataformas de redes sociais.

\section{Maravilhamento e desencantamento}

Num primeiro momento, a internet foi vista por muitos pesquisadores através da lente do ufanismo utópico. Nos anos 1990, a internet ainda estava restrita a poucos países e a um núcleo muito elitizado econômica e culturalmente. Naquele momento, Lévy (2015) vislumbrou a possibilidade de se criar uma inteligência coletiva, na qual os saberes seriam distribuídos por toda parte, valorizados e coordenados em tempo real de maneira a resultar em uma mobilização de competências voltadas para desenvolver o conhecimento entre as pessoas. $\mathrm{E}$ esse novo estágio do desenvolvimento social só seria possível de ser alcançado com o uso da rede como ferramenta para a construção de um novo padrão sociotécnico com potencial 
de promover uma renovação dos laços sociais por intermédio do conhecimento. Ele chegou a argumentar em favor de uma "hipótese 'utópica' de uma democracia direta acompanhada por computador - ou uma ágora virtual" (LÉVY, 2015, p. 57).

No entanto, não deixou de apontar que esse era um dos caminhos possíveis de serem construídos para uma tecnologia que ainda se encontrava na sua infância. A internet poderia, sem a interferência coletiva e consciente, resultar no aprofundamento das desigualdades econômicas e sociais, na imposição da supremacia do consumo e da sociedade do espetáculo: "A forma e o conteúdo do ciberespaço ainda são especialmente indeterminados" (LÉVY, 2015, p. II, grifo do autor). Ele reconhecia que as potencialidades positivas da internet dependiam de "decisões técnicas, [da] adoção de normas e regulamentos, [das] políticas tarifárias" (LÉVY, 20I5, p. II, grifo nosso). Mas, apesar do alerta, o autor estrutura um conjunto de ideias a fim de apontar os caminhos possíveis para alcançar a inteligência coletiva, entendida como constatação e projeto a um só tempo. Essa concepção se aproxima daquela expressa por Marshall McLuhan, sintetizada em uma entrevista à revista Playboy, registrada por Erik Davis:

um estado tecnologicamente engendrado de compreensão e unidade universais, um estado de absorção nos símbolos que poderia unir a humanidade em uma só família e perpetuar paz e harmonia coletivas. (MCLUHAN, I969 apud DAVIS, 1998, p. 300, tradução nossa).

Embora Davis (1998) contraste essa afirmação de McLuhan com outras do mesmo autor em sentido oposto, revestidas de pessimismo e igualmente deterministas em relação às mídias eletrônicas, Rüdiger (20I6, p. IIo) resgata, a respeito de McLuhan: "a revolução pacífica prometida pelo pensamento cibernético a ser implementada com o desenvolvimento das novas tecnologias de comunicação encontrou em seus escritos a devida elaboração".

Até o início dos anos 2000, a topologia de redes baseadas em protocolos abertos, resilientes e interoperáveis apontava para seu potencial democrático e de expansão. Em função de tais características, Castells (2014, posição 223) afirmava que as "redes sociais de internet [...] são espaços de autonomia, muito além do controle de governos e empresas", valorizando a potência transformadora que enxergava em tais tecnologias. O autor se ancorava na topologia da internet para afirmar que "uma estrutura social com base em redes é um sistema aberto altamente dinâmico suscetível de inovação sem ameaças ao seu equilíbrio" (p. 566).

Tais perspectivas podem expressar aspectos importantes da aparência dos fenômenos relacionados ao uso da internet e, em alguns casos, mais especificamente das redes sociais, por ressaltarem as possibilidades objetivamente oferecidas pelas ferramentas. Mas, ao 
ignorar ou relativizar a necessária articulação do desenvolvimento tecnológico com as relações de produção, não poderiam estar mais longe da essência desse processo.

O otimismo presente nas análises de tão referenciados autores remete à crítica desenvolvida por Álvaro Vieira Pinto (2005) às teorias cibernéticas que se pautam por um "maravilhamento" do ser humano diante das próprias obras - o desenvolvimento de tecnologias -, apressando-se em anunciar o fim da história, em um extremo; ou apontar a ameaça de a sociedade ser dominada e dirigida por cérebros eletrônicos, em outro. Embora Vieira Pinto estivesse dialogando com teorias das décadas de I960 e I970, a crítica mostra-se absolutamente pertinente em relação a diversas leituras a respeito do desenvolvimento das redes de internet, inteligência artificial e outras tecnologias contemporâneas. O maravilhamento com as possibilidades oferecidas pela internet das coisas, a própria conceituação de internet de todas as coisas, cidades inteligentes e educação OnLIFE são apenas alguns exemplos ilustrativos. Circula em meios institucionais diversos a ideia de que "o código redefine, ontogeneticamente, as condições de possibilidade do mundo" (ACCOTO, 20I7, p. I3 apud SCHLEMMER; FELICE; SERRA, 2020). Atualmente, o discurso centrado no determinismo tecnológico com base numa narrativa de maravilhamento com as possibilidades democráticas ou evolutivas oferecidas por ferramentas cibernéticas faz parte da construção ideológica do grande capital concentrado no Vale do Silício.

Enquanto Pierre Lévy (2015, p. 39) alega que a "economia girará - como já o faz - em torno do que jamais se automatizará completamente, em torno do irredutível: a produção do laço social, o "relacional'", Vieira Pinto alerta para a importância de considerar as origens socioeconômicas das inovações tecnológicas:

Quando nos extasiamos diante dos milagres da tecnologia moderna e construímos uma visão do mundo tendo por concepção central a infinita expansibilidade do nosso poder criador, a primeira coisa a reconhecer, logo depois de haver moderado um pouco o cândido entusiasmo manifestado pelos técnicos, é que toda possibilidade de avanço tecnológico está ligada ao processo de desenvolvimento das forças produtivas da sociedade, a principal das quais cifra-se no trabalho humano. Tal desenvolvimento necessariamente conduz a fraturas, a saltos qualitativos, pelos quais se instalam em certos momentos novas formas de produção. Fica entendido que uma filosofia tecnológica, para ser autêntica, tem de fundar-se na teoria das mudanças no modo de produção social.[...]A reflexão sobre a técnica que [...] exclui a significação do homem e de seu esforço intelectual em racionalizar os dados da realidade para se aproveitar dos recursos oferecidos, tira-lhe toda a objetividade.(VIEIRA PINTO, 2005, p. 49). 
Em função dessa relação intrínseca com o desenvolvimento das forças produtivas da sociedade, o próprio desenvolvimento da internet contribuiu para alterar essa visão utópica de alguns autores. Isso porque, ao longo dos anos, a própria ideia de uma rede de redes aos poucos se partiu e perdeu seus nós à medida que foi sendo ocupada por plataformas privadas que capturaram o fluxo e a dinâmica de trocas para dentro do seu território particular. A sociedade em rede foi suplantada pelos novos monopólios das Big Techs, grandes empresas que passaram a ter um poder desproporcional, dominando o mercado financeiro, industrial, de serviços e de produção simbólica. A idealização de uma economia capitalista baseada na inovação, globalização e concentração descentralizada pensada por Castells (2007) foi substituída pelo capitalismo de plataformas (SRNICEK, 2OI8) ou sociedade de plataformas (VAN DIJCK; POELL; WALL, 20I8).

A mesma internet que havia sido exaltada pelo seu potencial democrático, foi apropriada e dominada por grandes empresas que aceleraram a interconexão e interdependência econômica entre as nações, radicalizando uma globalização dependente que, como dizia Milton Santos (200I), impõem-se para a maioria da humanidade como uma "fábrica de perversidades".

Dessa maneira, ao passo que as características de interação que permitem práticas de compartilhamento e colaboração anteriormente listadas são constituintes da internet, seu funcionamento comandado pelo capital apresenta também outros atributos:

\footnotetext{
As gigantes da web, como Google, Amazon, Facebook, Apple e Microsoft, adquiriram um poder extraordinário, algo que eu não havia pensado anos atrás. Elas têm um monopólio sobre a memória mundial e registram quase tudo que acontece na internet. Além de serem as companhias mais ricas do mundo, faz tempo que elas ultrapassaram as empresas do setor de energia, têm todos os dados, as tecnologias mais potentes e oferecem as infraestruturas necessárias para a comunicação entre as pessoas. Elas estão desenhando uma nova forma de poder econômico, o que é evidente, mas sobretudo político. Muitas funções sociais e políticas, que são funções tradicionais dos Estados-nação, estão passando para essas companhias. (LÉVY, 2020, s/p).
}

\section{O poder econômico das plataformas}

Como consequência e ilustração desse processo, entre 2007 e 2017 as cinco maiores companhias empresariais do mundo no mercado de capitais foram substituídas, a exceção de uma: Microsoft. Todas as outras, Exxon Mobil, General Eletric, Citigroup e Shell Oil, saíram da lista para dar lugar a Apple, Alphabet ("empresa mãe" da Google), Amazon e Facebook. 
Todas são empresas de tecnologia da informação e da comunicação, mas cada uma delas domina um nicho dessa indústria (ORMAY, 20I8).

O entendimento de como se deu esse processo pode ser extraído da explicação oferecida por Marcos Dantas (2019) sobre como o desenvolvimento da internet propicia a constituição de plataformas digitais que se configuram como praças de mercado (marketplaces), à medida que colocam produtores e consumidores em contato, independentemente da natureza de sua atividade (se é um site de buscas, um aplicativo de música ou redes/mídias sociais). A presença de diversos vendedores em um mesmo lugar gera competição, mas também atrai ainda mais consumidores, ao passo que a presença de muitos consumidores facilita a troca de informação entre eles sobre preços de produtos, de modo que é atrativo tanto para consumidores quanto para vendedores fortalecer um mesmo lugar. Assim, os postos dominantes no mercado das plataformas digitais serão ocupados por aqueles que, por alguma razão em dado momento, consigam se mostrar mais atrativos. As plataformas se beneficiam do efeito de rede: seu valor cresce na mesma medida que o número de usuários; e se o valor cresce, mais usuários se interessarão, lógica que favorece a concentração (monopólio), sendo esse mercado dominado por um pequeno grupo de gigantescas corporações.

Com base nessas alterações no cenário, cabe entender o papel das plataformas de internet no capitalismo contemporâneo. O termo "plataforma" é específico o suficiente para indicar a captura da vida digital em um ambiente fechado, controlado e administrado como um monopólio, como se fosse uma praça de mercado privada (HANDS, 20I3; DANTAS, 20I7). "Plataforma" é um termo sugestivo de um elemento de abertura e neutralidade que captura aspectos de transações de informação entre diferentes partes, ao mesmo tempo mantendo o controle. Ainda, as plataformas oferecem serviços públicos e se constituem como espaços públicos, mas fazem isso por ganhos privados, pois são sociedades empresárias (GILLESPIE, 2OIO) que constituem monopólios (SRNICEK, 2OI8), cujas receitas permanecem extremamente concentradas nos países de origem - em regra, Estados Unidos ou, no máximo, outro país desenvolvido. Tal configuração da distribuição de recursos informacionais no mundo indica o enorme poderio econômico e político das plataformas, caracterizando o imperialismo de plataforma (JIN, 20I5).

Ao considerar este debate sobre a noção de plataformas, de acordo com o modelo de negócios, é possível caracterizá-las ainda como companhias que oferecem infraestrutura para fazer a interação entre usuários (pessoas e empresas), baseada na monetização, e na coleta e no tratamento de dados pessoais processados por algoritmos. Essas empresas têm fortes tendências monopolistas (com concentração vertical e horizontal) impulsionadas pelos efeitos de rede (VAN DIJCK; POELL; WALL, 20I8; SRNICEK, 2OI8). Ou, como na definição de Dantas (2017, p. 3): 
Entenderemos por plataformas da internet um espaço-tempo articulado e conectado por redes físicas digitais de comunicação e de processamento de informação, no qual dois ou mais usuários podem interagir diretamente, interação esta, porém, facilitada e observada pelo operador, ou proprietário, da plataforma. Os usuários da plataforma podem ser compradores e vendedores, anunciantes publicitários, desenvolvedores de softwares, membros de redes sociodigitais etc.

Promovidas como comunitárias, as grandes plataformas digitais estabelecem medidas de cercamento. Oferecem soluções e facilidades tecnológicas para atrair milhões de usuários - como feeds de notícias, mensagens instantâneas, mecanismos técnicos utilizados em anúncios e controles de privacidade. Trata-se de recursos protegidos por direitos de propriedade intelectual, geralmente patentes, que, como barreiras à entrada da concorrência (via imitação), configuram os monopólios digitais.

Como expõe Trebor Scholz (2017), há uma massa de corpos sem nome escondida por trás da tela, exposta à vigilância no ambiente de trabalho, à espoliação da multidão, ao roubo de salários e softwares proprietários.

Dados são o insumo central desse novo tipo de empresa, cuja prestação de serviço na verdade é o pretexto para sua finalidade principal: extrair a maior quantidade possível de dados e utilizá-los para otimizar processos de produção, desenvolver um conhecimento interno sobre as preferências de seus usuários, controlar os trabalhadores e, com isso, criar novos produtos e serviços e oferecê-los para anunciantes e outras empresas. O que antes era um aspecto secundário do negócio dessas empresas, tornou-se o fator principal (SRNICEK, 2OI8).

Assim, os novos modelos de negócio que vêm sendo experimentados nas últimas décadas, absolutamente imbricados com o capital financeiro, como demonstra Dantas (2019), têm por base a captação, a sistematização e o direcionamento de dados produzidos por milhões de usuários (trabalho semiótico) por meio de algoritmos (capital fixo) com o objetivo de transportar informação o mais rápido possível entre compradores e vendedores, fazendo com que o tempo de realização do capital chegue ao limite de zero. Por isso, quanto mais usuários uma plataforma tiver, quanto maior for a interação, mais dados ela vai extrair, mais valor vai acumular e maior será seu poder de mercado. O que explica essas empresas precisarem desenvolver mecanismos para que seus usuários estejam conectados e interagindo por mais tempo (DANTAS, 20I7). 
Morozov (2018, p. 34) aponta que o modelo de capitalismo "dadocêntrico" converte toda a existência humana em ativos rentáveis, "nossos relacionamentos, nossa vida familiar, nossas férias, e até o nosso sono", em uma atualização digitalizada da constatação de Guy Debord (20I7, p. 54, grifos do autor): "o espetáculo é o momento em que a mercadoria ocupou totalmente a vida social".

\section{Democracias enviesadas}

Esse grande conjunto de dados coletados faz as vezes de um portfólio de tendências culturais e sociais sobre as quais serão direcionados aos consumidores produtos e serviços com o objetivo de lucro. As empresas que primeiro obtêm essas informações ficam mais bem posicionadas na corrida concorrencial. Essa é a emergência da ciência de dados, dedicada à extração de informações com base nos dados coletados nas plataformas digitais. A psicometria, que associa dados a padrões da psicologia humana, é uma área desse vasto novo campo de conhecimento, a qual tem sido usada não apenas para vender produtos, como também eleger políticos. $O$ tema ganhou relevância no debate público com o escândalo Facebook-Cambridge Analytica, quando dados vazados de 87 milhões de estadunidenses foram utilizados na campanha de Donald Trump à presidência (O ESCÂNDALO, 20I8).

A Cambridge Analytica desenvolveu um método de direcionamento de conteúdos de maneira microssegmentada, com base no uso de dados pessoais para construir perfis de usuários de acordo com o modelo desenvolvido para avaliar indivíduos em cinco traços de personalidade mapeados por estudos de comportamento: extroversão; amabilidade; consciência ou confiabilidade; estabilidade emocional ou neuroticismo; e abertura, cultura ou intelecto(GOLDBERG, 1992). Em torno desses perfis são desenvolvidos outros marcadores e microperfis com base na sua extensão, por exemplo.

Esses cinco fatores - Big Five - favorecem exatamente a disseminação de conteúdos de caráter moral-emocional segundo cada perfil. Esse processo tem se sofisticado com as tecnologias digitais de captura de dados pessoais, particularmente a ubiquidade das redes sociais. O direcionamento de conteúdos usando microssegmentação - principalmente fake news, conteúdos de ódio e que despertam medo - tem sido prática comum em processos políticos e sociais (Brexit, eleições no Brasil e no Equador, e informações sobre a pandemia).

Ou seja, o emprego das técnicas de psicometria aplicadas ao direcionamento de conteúdos usando seleção algorítmica nas plataformas de internet trouxe uma mudança de foco na seleção de características que diferenciam grupos de indivíduos para fins de publicidade e marketing político. No paradigma anterior (dos meios de comunicação de massa), o foco era em perfil socioeconômico-cultural. No novo, o público-alvo das mensagens é definido a partir da 
resposta psicológica, emocional e motivacional. Outra mudança importante é que, no paradigma anterior, o intermediário entre a informação e a sociedade eram empresas jornalísticas, nas quais a seleção, a produção e a distribuição dos conteúdos eram realizadas por seres humanos. Agora, no cenário no qual há bilhões de pessoas conectadas 24 horas por dia, sete dias por semana em todos os cantos do planeta produzindo os próprios conteúdos, o intermediário entre o conteúdo e a sociedade é um sistema automatizado.

A retórica do Vale do Silício tenta sedimentar a ideia de que os algoritmos de aprendizagem de máquina que atuam no interior dessas plataformas sociodigitais são neutros. Mas não são. Mesmo sendo sistemas matemáticos, o algoritmo, na sua etapa inicial, é desenvolvido com base em instruções dadas por uma equipe de profissionais, com base na modelagem de um problema, para atender a objetivos funcionais a serem alcançados nas etapas de operação. Essas etapas são dependentes de entradas de um conjunto de dados estruturados, pelos quais os algoritmos se aprimoram para tomar decisões com mais eficácia, o que, no caso das plataformas de internet, é otimizar as interações no seu interior, de modo a manter seus usuários mais tempo conectados.

O algoritmo, portanto, não é um sistema matematicamente neutro ou objetivo, uma vez que nele são incorporados dados que representam um acúmulo de rastros sociais, históricos e culturais que influenciam no seu funcionamento (bias). E, também, porque seu objetivo final não é melhorar o resultado das trocas simbólicas e o processo comunicativo visando ao aprimoramento do debate público, mas sim capturar a atenção para aumentar a coleta de dados e a acumulação de capital, numa nova economia política que tem a mineração de dados como meio de negócio.

O algoritmo não tem atributos para definir suas tarefas por meio de uma análise ética, contextualizada histórica, cultural e socialmente. Também não identifica nuances discursivas, nem intencionalidades. E é esse sistema que está, atualmente, substituindo o julgamento (ético, moral, contextualizado; observando nuances discursivas e impactos sociais) realizado por pessoas nos processos de comunicação (ROMANINI; MIELLI, 2O2I).

Ressalte-se que a intermediação realizada por seres humanos no exercício de suas profissões em empresas de comunicação não é isenta de viés e erros de todos os tipos. No entanto, podem ser mais facilmente identificáveis e questionados publicamente. Essas profissões e empresas operam (ou deveriam operar) com base em um conjunto de diretrizes éticas, morais e legais. E, caso não as sigam, podem ser questionadas e até responsabilizadas por isso.

Já no caso da intermediação algorítmica, isso, hoje, não é possível. Principalmente porque por detrás de argumentos técnicos e jurídicos, as empresas se furtam da responsabilidade sobre 
as consequências da ação dos algoritmos. A ausência de transparência é uma política deliberada e faz parte do modelo de negócios dessas plataformas monopolistas digitais.

Não se trata de dizer que, no período anterior à internet, os processos de comunicação se davam de maneira neutra ou imparcial. Sabe-se que os grandes veículos de comunicação adotavam critérios de seleção e tratamento do que chegaria à condição de notícia como base no que Abramo (2016) chamou de padrões de manipulação: ocultação, fragmentação, inversão e indução. Mas pode-se dizer que havia um jogo em que as regras eram conhecidas por todos os jogadores. A mídia já utilizava informações (dados) coletados por pesquisas de campo - quantitativas e qualitativas - que tinham como objetivo testar discursos mais adequados para determinados públicos e buscar a melhor narrativa para influenciar a opinião pública. Nas plataformas de internet, usuários, produtores e consumidores de conteúdos não conheciam essas regras, o que torna o potencial de manipulação e seus impactos ainda maiores do que os anteriores.

Isso porque o funcionamento dos algoritmos é totalmente opaco (desde o seu desenvolvimento). Eles executam de maneira instantânea e repetitiva a instrução que lhes foi dada. Usuários das plataformas de redes sociais e a sociedade não têm acesso às informações sobre nenhuma das etapas envolvendo seu desenvolvimento: parâmetros de modelagem; quais classes de dados são acessadas para realizar as entradas; quais as saídas projetadas e quais estão sendo efetivamente geradas; se os resultados do funcionamento do algoritmo estão dentro dos desejados e quais são os indesejados etc. Além disso, algoritmos são patenteados e classificados como segredo industrial e, portanto, não há mecanismo de auditoria sobre esses sistemas.

\section{Considerações finais}

Ao considerar o alcance do uso da internet na produção e na vida cotidiana das sociedades, diversos estados nacionais vêm buscando criar regulamentações de acordo com as demandas e os debates pertinentes a cada realidade. No Brasil, foram debatidos e aprovados o Marco Civil da Internet (MCI, Lei no 12.965/20I4) e a Lei Geral de Proteção de Dados Pessoais (LGPD, Lei no 13.709/2018). Além desses marcos legais importantes, membros do legislativo têm discutido e promovido alterações em algumas legislações, a exemplo das regras eleitorais, que passaram a contemplar a propaganda política na internet. Há, ainda, uma miríade de propostas que tramitam no Congresso Nacional a respeito de fake news.

Embora o MCI e a LGPD sejam instrumentos importantes para estabelecer marcos institucionais e princípios de atuação dos poderes públicos em relação às novas tecnologias $\mathrm{e}$ seus usos, conforme argumentam Rodrigues, Bonone e Mielli (2020, p. 48) ao debater 
aspectos que deveriam ser enfrentados no combate à desinformação, é necessário que as políticas públicas enfrentem questões como "regulação econômica e obrigações de transparência para as plataformas; governança de algoritmos; proteção de dados pessoais; e mecanismos de enfrentamento aos comportamentos maliciosos - incluindo abuso de poder econômico". Além disso, regulações nacionais são insuficientes para combater o poderio de monopólios transnacionais que captam, sistematizam e direcionam dados, intervindo concretamente nos rumos de democracias inteiras e produzindo alterações nas relações sociais e de produção à medida que expandem sua atuação.

A primeira questão que se levanta como fundamental para enfrentar essa lógica de apropriação de dados e de produções coletivas é combater a naturalização desses novos modelos de negócio como inevitáveis. Como já dito, o modelo de negócios, a arquitetura e o design dessas plataformas não foram desenvolvidos para aprimorar o debate público.

Nessa perspectiva, um ponto de partida importante é a defesa do acesso à internet como serviço público, empreendida por alguns setores na ocasião do debate sobre um Plano Nacional de Banda Larga. Essa discussão precisa ser retomada como estruturante para o desenvolvimento do país - em termos de Brasil, mas serve para os demais Estados nacionais. Toda a infraestrutura de distribuição de internet precisa ser entendida como um serviço público justamente pela importância estratégica ao funcionamento de indústrias, comércio, pesquisa científica, transações financeiras, organização e armazenamento de dados e informações e toda a infinidade de atividades que passam pelo uso da internet nos dias atuais. Ademais, é estratégico para desmontar uma das bases para a disseminação de conteúdos tóxicos que é o modelo de acesso móvel via zero rating, que radicaliza o aprisionamento dos usuários no interior das plataformas, impedindo a checagem de informações em sites da internet, a busca de multiplicidade de fontes, gerando um sistema circular de retroalimentação de conteúdos entre plataformas "gratuitas".

Entre muitos aspectos que precisam - e devem - ser enfrentados no debate sobre regulação de plataformas, um que talvez esteja tendo menos relevância é o debate sobre o segredo industrial e patenteamentos dos modelos algorítmicos utilizados para a seleção, distribuição, ampliação e redução de alcance, entre outros mecanismos de direcionamento de conteúdos no interior das plataformas de redes sociais. De acordo com a base de dados PATENTSCOPE, ${ }^{1}$ da Organização Mundial da Propriedade Intelectual (OMPI), em o3 de março de 2018, a Google detinha 35.062 patentes; o Facebook, 6.625; e a Uber I.699. As patentes garantem o monopólio de exploração comercial das tecnologias que sustentam as

${ }^{1}$ Disponível em:<https://patentscope.wipo.int/search/pt/search.jsf>. Acesso em: 12 nov. 2021. 
plataformas digitais, representando a demarcação de um território a partir do qual a acumulação de capital contemporânea geraria um novo tipo de rentismo, fundado no monopólio da informação e do conhecimento sobre tecnologias estratégicas.

Outro impacto danoso oriundo da opacidade dos algoritmos aliada à ausência de problematização sobre sua lógica de funcionamento, é que a sociedade acaba sendo levada a focar suas lentes nas consequências e não nas causas da desagregação do debate público. Nesse sentido, legislações e iniciativas regulatórias para mitigar os efeitos deletérios da circulação de informação mediada em plataformas de internet têm sido discutidas em muitos países. No entanto, são insuficientes para enfrentar as causas desses problemas. É necessário explorar ideias para ir além de regulações pontuais e pensar em caminhos mais estruturantes para criar salvaguardas ao livre fluxo de informações que garantam diversidade e pluralidade indispensáveis à construção de uma esfera pública que propicie o fortalecimento da democracia, e não sua corrosão.

\section{Referências}

ABRAMO, P. Padrões de manipulação da grande imprensa. São Paulo: Fundação Perseu Abramo, 2016.

BRASIL. Lei n- 12.965 , de 23 de abril de 20I4. Estabelece princípios, garantias, direitos e deveres para o uso da Internet no Brasil. Diário Oficial [da] República Federativa do Brasil, Brasília, DF, 23 abr. 20I4.

BRASIL. Lei nº 13.709, de I 4 de agosto de 20I8. Lei Geral de Proteção de Dados Pessoais (LGPD). Diário Oficial [da] República Federativa do Brasil, Brasília, DF, I4 ago. 2018.

CASTELLS, M. A sociedade em rede. A era da informação: economia, sociedade e cultura. 6. ed. Tradução Klauss Brandini Gerhardt. São Paulo: Paz e Terra, 2007. I v.

CASTELLS, M. Redes de indignação e esperança: movimentos sociais na era da internet. Tradução Carlos Alberto Medeiros. 2. ed. Rio de Janeiro: Zahar, 20I4. E-book Kindle.

DANTAS, M. Internet: praças de mercado sob controle do capital financeiro. 20I7. Trabalho apresentado ao LX Congresso Brasileiro de Ciências da Comunicação, Curitiba, 2017. Disponível em: $<$ http://marcosdantas.com.br/conteudos/wpcontent/uploads/20I7/II/Comunica\%C3\%A7\%C3\%A30-20I7_modelo_corrigido.pdf $>$. Acesso em: 19 ago. 202I.

DANTAS, M. The financial logic of internet platforms: the turnover time of money at the limit of zero. TripleC, v. I7, n. I, p. I32-158, 2019.

DAVIS, E. Technosis. Nova York: Three Rivers, 1998. 
DEBORD, G. A sociedade do espetáculo. Tradução Estela dos Santos Abreu. 2. ed. Rio de Janeiro: Contraponto, 2017.

GILLESPIE, T. The politics of platforms. New Media and Society, v. I2, n. 3, p. 347-364, 2010.

GOLDBERG, L. R. The development of markers for the big-five factor structure. Psychological Assessment, v. 4, n. I, p. 26-42, 1992.

HANDS, J. Introduction: politics, power and 'platformativity'. Culture Machine, v. I4, p. I-9, 2013.

JIN, D. Y. Digital platforms, imperialism and political culture. New York: Routledge, 2015.

LÉVY, P. A inteligência coletiva: por uma antropologia do ciberespaço. Tradução Luiz Paulo Rouanet. São Paulo: Folha de S. Paulo, 2015. I6 v. (Coleção Folha Grandes Nomes do Pensamento).

LÉVY, P. ‘Gigantes da web são novo Estado', diz Pierre Lévy. Entrevista concedida a Daniela Fernandes. Paris: Valor Econômico, 23 out. 2020. Disponível em: <https://valor.globo.com/eue/noticia/2020/IO/23/gigantes-da-web-sao-novo-estado-diz-pierre-levy.ghtml\#>. Acesso em: I9 ago. 2O2I.

MOROZOV, E. Big Tech: a ascensão dos dados e a morte da política. São Paulo: Ubu, 2018.

O ESCÂNDALO que fez o Facebook perder US\$ 35 bilhões em horas. BBC News Brasil, 19 mar. 2018. Disponível em: <https://www.bbc.com/portuguese/internacional-43466255>. Acesso em: 25 mar. 202I.

ORMAY, L. Propriedade intelectual e renda no capital-informação. 236 f. 20I8. Tese(Doutorado em Ciência da Informação) - Instituto Brasileiro de Informação em Ciência e Tecnologia, Escola de Comunicação, Universidade Federal do Rio de Janeiro, Rio de Janeiro, 2018.

RODRIGUES, T. C. M.; BONONE, L. M.; MIELLI, R. Desinformação e crise da democracia no Brasil: é possível regular fake news? Confluências, Niterói, v. 22, n. 3, p. 30-52, 2020. Disponível em: $<$ https://periodicos.uff.br/confluencias/article/view/45470/27124 $>$. Acesso em: I9 ago. $2 \mathrm{O} 2 \mathrm{I}$.

ROMANINI, A. V.; MIELLI, R. A comunicação dominada pelas "big techs" digitais: superabundância informativa, espetáculo, alienação e fabricação de sentido no mundo algorítmico. Revista Eptic, v. 23, n. I, p. I42-I6I, 202I. Disponível em: $<$ https://seer.ufs.br/index.php/eptic/article/view/I4658/II592>. Acesso em: I5 ago. 2O2I.

RÜDIGER, F. As teorias da cibercultura: perspectivas, questões e autores. 2. ed. Porto Alegre: Sulina, 2016.

SANTOS, M. Por uma outra globalização: do pensamento único à consciência universal. 6. ed. Rio de Janeiro: Record, 200I. 
SCHLEMMER, E.; FELICE, M. Di; SERRA, I. M. R. de S. Educação OnLIFE: a dimensão ecológica das arquiteturas digitais de aprendizagem. Educ. rev., v. 36, 2020. Disponível em: $<$ https://doi.org/IO.I590/OIO4-4060.76120 >. Acesso em: I9 ago. 202I.

SRNICEK, N. Capitalismo de plataformas. Buenos Aires: Caja Negra, 2018.

SCHOLZ, T. Cooperativismo de plataforma. São Paulo: Elefante; Autonomia Literária; Fundação Rosa Luxemburgo, 2017.

VAN DIJCK, J.; POELL, T.; WALL, De M. The platform society. Oxford: Oxford University Press, 2018. VIEIRA PINTO, A. Oconceito de tecnologia. Rio de Janeiro: Contraponto, 2005. I v. 